\title{
Anthropogenic impact on the local ecosystems: the main factors
}

\author{
Alla Ovcharenko ${ }^{1, *}$, Liparit Badalyan ${ }^{1}$, Svetlana Kucherenko $^{1}$, Alexey Lebedev ${ }^{1}$, and \\ Khamzat Gazgireev ${ }^{2}$ \\ ${ }^{1}$ Don State Technical University, 1, Gagarina sqr., 344003, Rostov-on-Don, Russia \\ ${ }^{2}$ Ingush State University, I.B. Zyazikova awe., 7, 386001, Magas, the Ingush Republic, Russia
}

\begin{abstract}
The represented study aims to assess the technogenic impact on the human-transformed landscape on the example of one of the Russian Federation regions. The hydrocarbon fuel consumption and carbon dioxide emissions in the local area are proposed to use as the main indicators of anthropogenic impact on the ecosystem. The research accents the necessity of taking into account the motor vehicles' negative impacts on the natural environment. The integrated application of suggested criteria allows assessing the actual state of the environment, to trace the correspondences between fuel consumption and the environmental pollution, and to formulate recommendations on the reduction of ecological and economic damage to the ecosystems.
\end{abstract}

\section{Introduction}

Condition assessment of the environment transformed by dynamically changing technogenic impacts is one of the most important tasks of environmental protection services when developing sustainability guidelines for the local area. Generally, there is a specifically outlined complex of environmental assessment criteria for every region which considers its geoenvironmental conditions and human-caused impacts.

The local territory's hydrocarbon fuel consumption level is one of the fundamental factors of anthropogenic impacts on the ecosystem. Data on industrial facilities and the population's consumption of fuel serves as a criterion of the region's sustainability [ $1-4]$.

Due to sufficiently correct evaluation and prediction of ecological situations and technogenic impacts, the protection of human-transformed ecosystems amounts to reducing the negative effects to the levels corresponding to the adopted environmental standards. The emission of carbon dioxide $\left(\mathrm{CO}_{2}\right)$ is also one of the accepted tracers of anthropogenic activities [5,6]. The air pollution analysis often overlooks the negative impacts caused by motor vehicles, despite automobiles' being one of the main polluters, especially for the urbanized, densely populated areas [7]. That's why it is highly relevant to obtain the correct data on territorial pollution.

\footnotetext{
*Corresponding author: alunia_020788@mail.ru
} 
The represented study aims to assess of technogenic impacts on the human-transformed landscape on the example of one of the Russian Federation regions. The following problems solution is the basis for its achievement:

1. The analysis of the territory's hydrocarbon fuel consumption level.

2. The estimation of carbon dioxide air pollution by stationary and mobile sources.

The nowadays transport emission regulations established in the EU and the USA require applying individual automotive on-board diagnostics (OBD) and portable emissions measurement systems (PEMS) [8]. Nevertheless, the analytical models for exhaust gases emissions and fuel consumption of motor vehicles still present a matter of scientific interest during the global economic crisis and in the post-crisis period, specifically, for countries with outdated car fleets.

The analysis of up-to-date studies in this field showed that there are many fuel consumption and emission evaluation models [9 - 14], differing by scale (macroscopic, mesoscopic, and microscopic) [7, 10], approaches (regression, load-based, and engine maps) $[10,11,14]$, inputs, etc. Each model has its advantages and disadvantages (sparseness and non-flexibility for engine maps, a possible lack of a physical interpretation for regression models, and complexity of computation for load-based models [10]).

The basis of authors model of motor vehicle fuel consumption and exhaust gases emissions evaluation is the kinematic and dynamic parameters of the automobile (velocity, acceleration, the relative power, etc.) [15] along with the data acquired by Russian researchers during the petrol and diesel cars tests (Kurov, Kolchin, Smajlis, etc.). The choice of mathematical simulations based on the fundamental principles of combustion theory and theoretical mechanics, along with the adequacy of theoretical theses and scientific conclusions, validate the model reliability.

The Ingush Republic had been chosen as representative subject. The obtained results may be used as basic benchmarks when developing a set of environmental criteria and sustainability goals for the local area. This approach allows using the whole territory of the Republic as a research subject, despite the diversity of geoenvironmental conditions (relief, climate, water bodies distribution, etc.) and an uneven territorial distribution of industrial facilities on its territory. The data on the factual pollution in the local area are supposed to apply in the following studies of ecosystems' ability to resist the technogenic influence, in particular, for calculation of the supply air volume which is needed in the processes of air exchange to facilitate the atmosphere self-purifying of contaminating substances.

\section{Materials and methods}

\subsection{Taking into account the hydrocarbon fuel consumption in the local area}

The inventory of hydrocarbon fuel consumers in the local territory should take into consideration not only stationary industrial facilities and residential properties but also motor vehicles.

The fuel mass flow rate (or traditionally applied volumetric flow indicator concerning gas fuel) is one of the most important vehicle exploitation indicators, which is calculated as follows:

$$
M_{G}=\frac{Q_{E G}}{V_{E G}},
$$

where $M_{G}$ is fuel mass flow rate of a single automobile, $\mathrm{kg} / \mathrm{s}\left(\right.$ or $\left.\mathrm{m}^{3} / \mathrm{s}\right) ; Q_{E G}$ is the exhaust gases volumetric flow, $\mathrm{m}^{3} / \mathrm{s} ; V_{E G}$ is the total volume of exhaust gases forming during the 
combustion of mass (or volumetric) fractions $m_{G}$ of elements per $\mathrm{kg}$ (or cubic meter) of fuel, $\mathrm{m}^{3} / \mathrm{kg}\left(\mathrm{m}^{3} / \mathrm{m}^{3}\right)$,

for liquid fuels, $\mathrm{m}^{3} / \mathrm{kg}$

$$
V_{E G}=22,4 m_{G} \cdot M_{E G},
$$

for gas fuel, $\mathrm{m}^{3} / \mathrm{m}^{3}$

$$
V_{E G}=m_{G} M_{E G}
$$

$M_{E G}$ is exhaust gases mass which is practically the same as the mass of liquid or gas fuel combustion products $M_{C P}, \mathrm{kmol} / \mathrm{kg}$.

Indeed, the nearly full combustion of fuel-air mixture occurs in the compressionignition engines, and trace substances which are products of side effects and diesel fuel incomplete combustion are estimated to be about $(0,02-1,0)$ percent of total emission volume. For the petrol engines, this quantity rarely exceeds 3.5 percent. Consequently, the $M_{E G}$ indicator can be used with adequate accuracy in the practical calculations instead of the $M_{C P}$. In the gas engines there is almost full combustion of air-fuel mixture. The previous studies provide acceptable theoretical relationships between the $M_{C P}$ and fuel's elemental composition along with excess air factor and theoretically required air volume for the total fuel combustion.

After approximate estimates of values and transformations, consistently adding into the formula (1) the respective values of the average elemental composition of the fuel along with the lower heating value and correlations between the exhaust gases volumetric flow rate and power characteristics of the automobile leads to the operational (the calculation error does not exceed 0.63 percent) formulae of mass flow rate for diesel fuel, $\mathrm{kg} / \mathrm{s}$

$$
M_{G}=0.0256 \cdot 10^{-6} \varphi \frac{\bar{N}\left(N_{n}-N_{\min }\right)+N_{\min }}{\eta_{i} \eta_{m}},
$$

for petrol, $\mathrm{kg} / \mathrm{s}$

$$
M_{G}=0.0247 \cdot 10^{-6} \varphi \frac{\bar{N}\left(N_{n}-N_{\min }\right)+N_{\min }}{\eta_{i} \eta_{m}},
$$

for gas fuel, $\mathrm{m}^{3} / \mathrm{s}$

compressed

$$
M_{G}=\frac{0.721 \cdot 10^{-6} \varphi \bar{\alpha} \alpha_{\max } \bar{N}\left(N_{n}-N_{\min }\right)+N_{\min }}{\left(\bar{\alpha} \alpha_{\max }+0.093\right) \eta_{i} \eta_{m}},
$$

liquefied

$$
M_{G}=\frac{0.544 \cdot 10^{-6} \varphi \bar{\alpha} \alpha_{\max } \bar{N}\left(N_{n}-N_{\min }\right)+N_{\min }}{\left(\bar{\alpha} \alpha_{\max }+0.042\right) \eta_{i} \eta_{m}}
$$

where $\varphi$ is a venting rate, $\bar{N}, N_{n}, N_{\text {min }}$ are respectively the relative, nominal and minimal engine's power (the minimal power is assumed to be the power of idle engine); $\eta_{i}$ and $\eta_{\mathrm{M}}$ are consistently an indicator and mechanical efficiency; $\bar{\alpha}$ and $\alpha_{\max }$ are respectively a relative and maximal excess air factor. 
The venting rate usually estimates as $1.05-1.1$. In the four-stroke reciprocating engine $\varphi$ does not exceed 1.25. When blowdown is absent or insignificant $\varphi$ is assumed to be equal 1 .

The calculation of the engine's relative power in correlation with cinematic and dynamic factors with its following transformation into coded values can be performed due to applying Lagrange's equation to the changes of the "engine - vehicle" system kinetic energy. While in the process, the time percentage of vehicles engines' operation modes should be taken into account [16].

The determination of the indicator and mechanic efficiency along with the relative excess air ratio comes down to the analysis of these parameters' empiric correlations with the engine load [16].

The $\alpha$ maximum values are represented in table 1 .

Table 1. Excess air ratio of internal combustion engines.

\begin{tabular}{|c|c|c|c|}
\hline \multirow{2}{*}{$\begin{array}{c}\text { Excess } \\
\text { air } \\
\text { factor }\end{array}$} & \multicolumn{3}{|c|}{ Engine } \\
\cline { 2 - 4 } & carburetor & injector & $\begin{array}{c}\text { compression- } \\
\text { ignition }\end{array}$ \\
\hline $\begin{array}{c}\text { Idle } \\
\text { mode }\end{array}$ & $\alpha_{\min }=0.86$ & $\begin{array}{c}\alpha_{\min }=0.96 \\
\alpha_{\min }=1.0 \text { (urban mode) }\end{array}$ & $\alpha_{\max }=5.0-6.0$ \\
\hline $\begin{array}{c}\text { Nominal } \\
\text { mode }\end{array}$ & $\alpha_{\max }=0.96$ & $\begin{array}{c}\alpha_{\max }=0.98 \\
\alpha_{\max }=1.1 \text { (urban mode) }\end{array}$ & $\alpha_{\min }=1.4-2.2$ \\
\hline
\end{tabular}

\subsection{The calculation of carbon dioxide emissions from stationary and mobile sources}

In general form, the carbon dioxide mass emitted by the combustion of any type of fuel is identified with the equation

$$
M_{f i}\left(\mathrm{CO}_{2}\right)=\frac{44}{12} \cdot B_{i} m_{f i}
$$

where $B_{i}$ is the carbon mass fraction of the $i^{\text {th }}$ kind of fuel, $\mathrm{kg} / \mathrm{kg} ; m_{f i}$ is the consumed fuel mass, $\mathrm{kg}$.

This study suggests using the formula (6) to assess the $\mathrm{CO}_{2}$ emission from the industrial facilities and the residential buildings.

The calculations of the carbon dioxide masses emitted from the mobile sources (motor vehicles) were performed with the use of the authors' method based on the logically sound math simulation of air pollution by the operating automobiles. The applying of this method allows to sufficiently determine the harmful substances mass flow rate, $\mathrm{g} / \mathrm{s}$, of ten components of exhaust gases (carbon monoxide, carbon dioxide, nitrogen oxides standardized to nitrogen dioxide, hydrocarbons averaged to $\mathrm{CH}_{1,85}$, sulfur dioxide, aldehydes standardized to $\mathrm{C}_{3} \mathrm{H}_{4} \mathrm{O}$, soot standardized to carbon, benz[a]pyrene, forms of lead averaged to lead and fuel ash).

\section{Results and discussion}

To define the fuel mass flow rate and yearly $\mathrm{CO}_{2}$ emissions from the mobile sources, the analysis of the Ingush Republic transportation park was performed with the use of the data provided by State road inspectorate in 2018 (table 2). 
Table 2. The composition of the Ingush Republic road motor vehicle fleet in 2018.

\begin{tabular}{|c|c|c|c|c|c|}
\hline \multirow{3}{*}{ Main consumer's feature } & \multicolumn{4}{|c|}{ Fuel type } & \multirow{3}{*}{$\Sigma$} \\
\hline & \multicolumn{2}{|c|}{ Petrol } & \multirow{2}{*}{ Diesel } & \multirow{2}{*}{ Gas } & \\
\hline & carburetor & injector & & & \\
\hline Cars & 33937 & 52877 & 4614 & 854 & 92282 \\
\hline $\begin{array}{l}\text { Light commercial and } \\
\text { commercial vehicles }\end{array}$ & 2497 & 2670 & 2888 & 370 & 8425 \\
\hline Heavy commercial vehicles & 2156 & 635 & 5759 & 46 & 8596 \\
\hline Buses & 296 & 177 & 404 & 2 & 879 \\
\hline Total & 38886 & 56359 & 13665 & 1272 & 110182 \\
\hline
\end{tabular}

Tables 3 and 4 represent the obtained results.

Table 3. The motor vehicles fuel flow rate, tons per year.

\begin{tabular}{|c|c|c|c|c|}
\hline \multirow{3}{*}{$\begin{array}{c}\text { Main consumer's } \\
\text { feature }\end{array}$} & \multicolumn{4}{|c|}{ Fuel type } \\
\hline & \multicolumn{2}{|c|}{ Petrol } & \multirow{2}{*}{ Diesel } & \multirow{2}{*}{ Gas* } \\
\hline & carburetor & injector & & \\
\hline Cars & 214047.446 & 250129.361 & 25463.743 & 134995.367 \\
\hline $\begin{array}{l}\text { Light commercial and } \\
\text { commercial vehicles }\end{array}$ & 20670.665 & 15787.71 & 20492.093 & 74968.956 \\
\hline $\begin{array}{l}\text { Heavy commercial } \\
\text { vehicles }\end{array}$ & 21247.38 & 5006.34 & 102158.901 & 35160.275 \\
\hline Buses & 3383.813 & 1604.788 & 5733.245 & 833.339 \\
\hline Total & \multicolumn{2}{|c|}{$\mathbf{5 3 1 8 7 7 . 5 0 3}$} & 153847.982 & 245957.937 \\
\hline
\end{tabular}

Where: "The volumetric flow rate of the gas fuel is measured in $10^{3} \mathrm{~m}^{3} /$ year.

Table 4. The carbon dioxide emissions from transportation, tons per year.

\begin{tabular}{|l|c|c|c|c|}
\hline \multirow{2}{*}{$\begin{array}{l}\text { Main consumer's } \\
\text { feature }\end{array}$} & \multicolumn{3}{|c|}{ Fuel type } \\
\cline { 2 - 3 } & \multicolumn{2}{|c|}{ Petrol } & \multirow{2}{*}{ Giesel } & \\
\cline { 2 - 3 } Cars & 580603.698 & 704322.592 & 65387.255 & 17246.416 \\
\hline $\begin{array}{l}\text { Light commercial } \\
\text { and commercial } \\
\text { vehicles }\end{array}$ & 52641.295 & 44005.61 & 50239.781 & 9423.627 \\
\hline $\begin{array}{l}\text { Heavy commercial } \\
\text { vehicles }\end{array}$ & 56611.519 & 13769.938 & 253921.624 & 4776.104 \\
\hline Buses & 9026.612 & 4285.482 & 14049.635 & 117.393 \\
\hline Total & \multicolumn{4}{|c|}{1880428.581} \\
\hline
\end{tabular}

The analysis of the fuel consumption by industrial facilities and residential buildings in the investigated region revealed that the natural gas is the primarily used fuel in the Ingush Republic (fig. 1, a). Consequently, the equation (6) transforms as follows

$$
M_{f i}\left(\mathrm{CO}_{2}\right)=\frac{44}{12} \cdot 0,75 V_{f} \rho_{n g},
$$

where $V_{f}$ is the consumed gas volume, $\mathrm{m}^{3} ; \rho_{n g}$ is the natural gas estimated density, $\rho_{n g}=$ $1,457 \mathrm{~kg} / \mathrm{m}^{3}$;

or

$$
M_{f i}\left(\mathrm{CO}_{2}\right)=4,00675 V_{f} \text {. }
$$



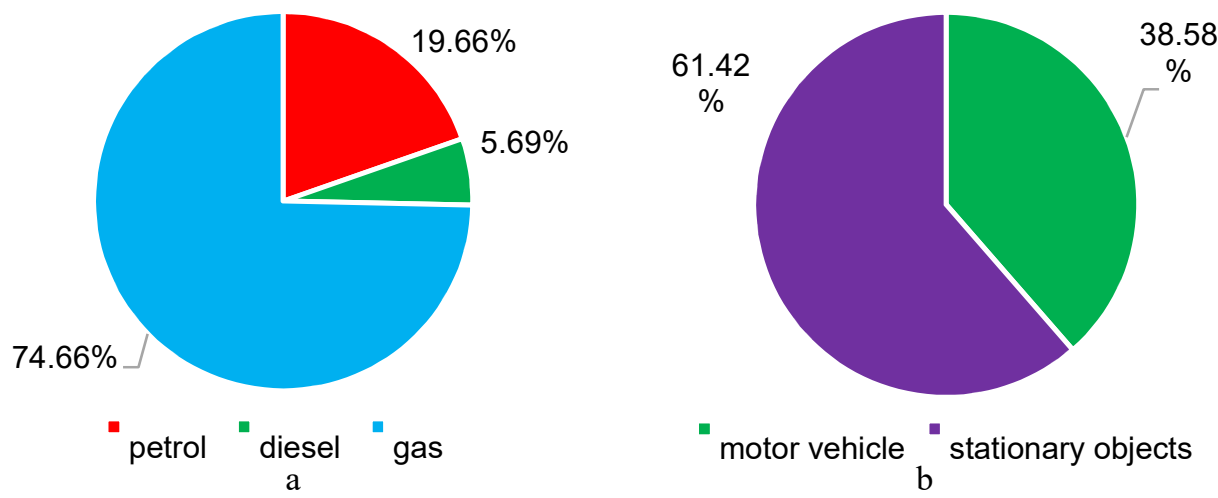

Fig. 1. Fuel consumption ratio in the Ingush Republic.

The Ingush Republic Regional gasification programme for 2018 - 2022 estimates the total natural gas consumption in 2019 as nearly 1.387 billion $\mathrm{m}^{3}$. The information represented in table 3 allows concluding the domination of the stationary objects (industrial and residential) among the natural gas consumers (nearly 82 percent). Besides, the fuel distribution (regardless of the fuel type) ratio (fig. 1, b) shows the motor vehicles' 40 percent of yearly fuel consumption.

The $\mathrm{CO}_{2}$ emission assessment performed with the use of represented method allows concluding the follows:

1. In 2019 the carbon dioxide emissions from stationary sources were about 5.524 million tons. This amount represented approximately 75 percent of the total yearly $\mathrm{CO}_{2}$ regional emission (fig. 2).

2. The inventory of polluters in the local area should include road transport: while often overlooked, it accounts for about 25 percent of gross $\mathrm{CO}_{2}$ emissions (see fig.2).

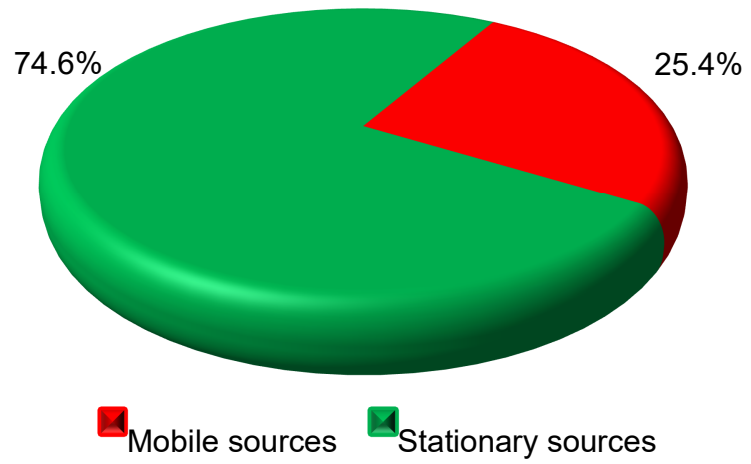

Fig. 2. The Ingush Republic carbon dioxide yearly emission ratio.

\section{Conclusion}

In the represented research, the hydrocarbon fuel consumption and the yearly carbon dioxide release represents the main indicators of technogenic impact in the local territory. The correlations between the fuel mass flow rate (along with exhaust gases emissions) and cinematic and dynamic characteristics of road vehicles provide a basis for the assessment methodology of chosen indicators for the mobile fuel consumers [16] while model based on 
the chemical properties of hydrocarbon fuels and statistical data on its consumption lies at the foundation of such methodology for industrial and residential facilities.

The performed studies on the anthropogenic impacts on the Ingush Republic ecosystems allow concluding that the primary fuel consumers in the region are stationary (residential and industrial) objects (see fig. 1, b). The major part of carbon dioxide emissions in the Republic is a result of their activities. However, the motor transport accounts for a considerable share of air pollution (nearly 25 percent, see fig. 2), which demonstrates the importance of assessment of technogenic impacts on the environment caused by automobiles. Due to uneven distribution of the industrial facilities, residential buildings and transport infrastructure on the republican territory, it makes sense to apply the more detailed approach of anthropogenic impacts evaluation (in particular, conducting the research in the each of the administrative areas of region). This way it will be possible to correct the acquired aggregated findings.

The integrated application of suggested criteria allows assessing the actual state of the environment, to trace the correspondences between fuel consumption and the environmental pollution, and to formulate recommendations on the reduction of ecological and economic damage to the human-transformed landscapes.

\section{References}

1. T. Hillman, A. Ramaswami, Environ. Sci. Technol. 44(6), 1902-1910 (2010) doi: 10.1021/es9024194

2. F. Martins, C. Felgueiras, M. Smitková, Energy Procedia 153, 107-111 (2018) doi:10.1016/j.egypro.2018.10.050

3. V.S. Ediger, Energy Procedia 56, 2-6 (2019) doi:10.1016/j.egypro.2018.11.073

4. S.A. Asongu, M. Oluwatoyin Agboola, A. Adewale Alola, F.V. Bekun, Sci. of The Tot. Environ. 712, 136376 (2020) doi:10.1016/j.scitotenv.2019.136376

5. V. Masson-Delmotte, P. Zhai, H.-O. Pörtneretal et al., Global Warming of $1.5{ }^{\circ} \mathrm{C}$ (IPCC, 2018)

6. P. Fragkos, K. Fragkiadakis, L. Paroussos, R. Pierfederici, S.S. Vishwanathan, A.C. Köberle, G. Iyere, C.-M. He, K. Oshiro, Energy Policy 118, 462-473 (2018) doi:10.1016/j.enpol.2018.04.002

7. W. Faris, H. Rakha, S.A.M. Elmoselhy, SAE Int. J. of Materials and Manufacturing 7(1), 129-146 (2014) doi:10.4271/2013-01-9094

8. J.D.K. Bishop, M.E.J. Stettler, N. Molden, A.M. Boies, App. Energy 183, 202-217 (2016) doi:10.1016/j.apenergy.2016.08.175

9. M. Ben Chaim, Efraim Shmerling, Int. J. of Mechanics 1(7), 10-17 (2013)

10. K.R. Den Braven, A. Abdel-Rahim, K. Henrickson, A. Battles, Modeling Vehicle Fuel Consumption and Emissions at Signalized Intersection Approaches: Integrating FieldCollected Data Into Microscopic Simulation (USA, University of Idaho, 2012)

11. M. Zhou, H. Jin, W. Wang, Transp. Res. Part D: Transp. and Env. 49, 203-218 (2016) doi: 10.1016/j.trd.2016.09.008

12. H.A. Rakha, K. Ahn, K. Moran, B. Saerens, E. Van den Bulck, Transp. Res. Part D: Transp. and Env. 16(7), 492-503 (2011) doi: 10.1016/j.trd.2011.05.008

13. G. Fontaras, T. Grigoratos, D. Savvidis, K. Anagnostopoulos, R. Luz, M. Rexeis, S. Hausberger, Energy 102, 354-364 (2016) doi: 10.1016/j.energy.2016.02.076 
14. M. Ben-Chaim, E. Shmerling, A. Kuperman, Energies 6, 117-127 (2013) doi:10.3390/en6010117

15. L. Badalyan, V. Kurdjukov, A. Ovcharenko, Matec Web of Conferences 196, 04065 (2018) doi:10.1051/matecconf/201819604065

16. L. Badalyan, V. Kurdyukov, A. Ovcharenko, A. Lebedev, D. Karakulkina, Advances in Engineering Research 191, 30-34 (2020) doi: 10.2991/aer.k.200202.007 